\title{
Seletividade de genótipos de eucalipto a doses de herbicidas
}

\section{Seletivicty of eucalyptus genotypes to herbicides rates}

\author{
Dirceu Agostinetto ${ }^{1}$; Camila Peligrinotti Tarouco ${ }^{2 *}$; Catarine Markus ${ }^{3}$; Ezequiel de \\ Oliveira $^{3}$; José Matheus Betemps Vaz da Silva ${ }^{3}$; Siumar Pedro Tironi ${ }^{3}$
}

\section{Resumo}

O objetivo deste trabalho foi quantificar a seletividade de herbicidas aplicados em pós-emergência na cultura do eucalipto em função de diferentes doses. $\mathrm{O}$ experimento foi realizado em casa de vegetação, pertencente a Faculdade de Agronomia Eliseu Maciel da Universidade Federal de Pelotas, no Município de Capão do Leão - RS, no período de janeiro a março de 2007. O delineamento experimental utilizado foi completamente casualizado, com quatro repetições. Os tratamentos foram arranjados em esquema fatorial, onde o fator A testou genótipos de eucalipto (E. globulus e E. saligna), o fator B comparou quatro herbicidas (isoxaflutole, oxyfluorfen, bispyribac-sodium e sethoxydim+diclosulam) e o fator C doses $(0,50,100,150$ e $200 \%)$ da dose média registrada para controle de plantas daninhas. As variáveis avaliadas foram fitotoxicidade, estatura, diâmetro do caule e matéria seca da parte aérea das plantas de eucalipto. O genótipo E. globulus é mais sensível aos herbicidas do que o E. saligna. A mistura dos herbicidas sethoxydim+diclosulam apresentou potencial para ser utilizada na cultura do eucalipto. O herbicida bispyribac-sodium foi o mais tóxico, enquanto o isoxaflutole, considerado como padrão, foi o mais seletivo aos genótipos estudados.

Palavras-chave: Eucalyptus spp, tolerância, fitotoxicidade

\begin{abstract}
The aim of this work was to quantify the herbicide selectivity applied at post-emergence of eucalyptus in different rates. The experiment was conducted in greenhouse conditions in the period from January to March 2007 at the Faculdade de Agronomia Eliseu Maciel in Universidade Federal de Pelotas - Capão do Leão-RS. Experimental design was completely randomized, with four replications. Treatments were in a factorial scheme: factor A - eucalyptus genotypes (E. globulus e E. saligna), factor B - herbicides (isoxaflutole, oxyfluorfen, bispyribac-sodium and sethoxydim+diclosulam), and factor $\mathrm{C}-$ rates of the registered average for weed control $(0,50,100,150$ e 200\%). Phytotoxicity, height, stem diameter and dry matter were evaluated. E. globulus genotype was more sensitive to herbicides than E. saligna. The mixture of the herbicides sethoxydim plus diclosulam showed potential to be used in eucalyptus. Bispyribac-sodium herbicide was the most toxic and isoxaflutole was the most selective to the studied genotypes.
\end{abstract}

Key words: Eucalyptus spp, tolerance, phytotoxicidade

\footnotetext{
${ }^{1}$ Professor Dr. da Universidade Federal de Pelotas (UFPEL), Faculdade de Agronomia Eliseu Maciel, Departamento de Fitossanidade, Campus Universitário, Caixa Postal 354, CEP 96010-900, Capão do Leão, RS. E-mail: dirceu_agostinetto@ufpel. edu.br

${ }^{2}$ Engenheira Agrônoma, mestranda do curso de Pós-Graduação em Fitossanidade da Universidade Federal de Pelotas (UFPEL). E-mail:milatarouco@gmail.com

${ }^{3}$ Discente do curso de Agronomia da Universidade Federal de Pelotas (UFPEL). E-mail: catarine.markus@gmail.com; oliveira. agro@gmail.com; mbetemps@yahoo.com.br, siumar.tironi@gmail.com

* Autor para correspondência
} 


\section{Introdução}

Atualmente as áreas de cultivo com eucalipto no Brasil correspondem a 3,75 milhões de hectares. No Rio Grande do Sul o eucalipto teve seu cultivo intensificado a partir da década 60, possuindo atualmente área plantada de 222 mil ha. Dentre as espécies de Eucalyptus mais utilizadas nos plantios florestais estão E. saligna, E. citriodora, E. urophylla, E. grandis, E. dunni e alguns híbridos (ABRAF, 2008).

As culturas florestais, como qualquer população vegetal, estão sujeitas a uma série de fatores ecológicos que, direta ou indiretamente, podem afetar o crescimento das árvores e a produção de madeira, carvão e celulose, entre outros produtos. Estes fatores podem ser divididos em fatores abióticos (como a disponibilidade de água, nutrientes do solo, $\mathrm{pH}$ do solo, luminosidade e outros) e bióticos (competição, comensalismo, predação e outros) (PITELLI; MARCHI, 1991).

Um dos fatores que afetam a produtividade da cultura é a interferência ocasionada pelas plantas daninhas. Segundo Pitelli (1987), interferência refere-se ao conjunto de ações que recebe uma determinada cultura ou atividade do homem, em decorrência da presença das plantas daninhas num determinado ambiente. Assim, em função da interferência exercida pelas plantas daninhas a cultura, faz-se necessário a adoção de métodos de controle visando minimizar os danos ocasionados.

Dentre os métodos disponíveis para o controle das plantas daninhas na cultura do eucalipto se destaca na linha de cultivo o controle químico, com a utilização de herbicidas, enquanto na entrelinha o controle mecânico, pelo uso de roçadeira, é o método mais utilizado. Devido a escassez de produtos registrados à cultura para controle seletivo em pós-emergência das plantas daninhas, o uso do controle químico deve ser muito cauteloso evitando causar injúrias à cultura. Os herbicidas registrados para o controle de plantas daninhas em pré e/ou pósemergência na cultura do eucalipto são oxyfluorfen, isoxaflutole, carfentrazone-ethyl, sulfentrazone, trifluralin, orizalin, imazapyr, fluazifop-p-butyl e azefenidin. Já, glyphosate, glufosinate e sulfosate são utilizados no manejo da área em pré-transplante ou em jato dirigido (AGROFIT, 2008).

Avaliando-se a tolerância de espécies de Eucalyptus a diferentes herbicidas, Silva et al. (1994), constataram que os herbicidas clethodim, haloxyfopmetil e trifluralin, não causaram fitotoxicidade às plantas de eucalipto. Para o herbicida oxyfluorfen as espécies $E$. grandis e E. saligna foram as mais tolerantes, E. camaldulensis foi intermediária e $E$. citriodora mais sensível. Segundo aqueles autores, as espécies E. grandis, E. saligna e E. camaldulensis recuperaram-se dos sintomas de fitotoxicidade, não inviabilizando o uso do herbicida em pré e em póstransplante.

Como as injúrias causadas pelos herbicidas à cultura podem reduzir sua produtividade, é importante conhecer o potencial de dano que o herbicida em questão poderá oferecer à cultura nas condições em que será aplicado e, assim, possibilitar a tomada de decisão com maior segurança sobre a viabilidade econômica do controle de plantas daninhas (SPADER; VIDAL, 2001).

O objetivo do trabalho foi quantificar a seletividade de herbicidas aplicados em pósemergência aos genótipos de eucalipto, em função de diferentes doses.

\section{Material e Métodos}

O experimento foi conduzido nos meses de janeiro a março de 2007, em delineamento completamente casualizado, com quatro repetições. Cada unidade experimental foi composta por um vaso com capacidade de oito litros, preenchidos com solo, onde foram transplantadas duas plantas de eucalipto, em idêntico estádio de desenvolvimento. O solo utilizado é classificado como Planossolo hidromórfico eutrófico solódico, pertencente à unidade de mapeamento Pelotas (EMBRAPA, 1999). 
As mudas foram produzidas por micro-estaquia, sendo transplantadas para os vasos com três meses de idade. A irrigação foi realizada diariamente ao entardecer.

Os tratamentos foram arranjados em esquema fatorial ( $2 \times 4 \times 5)$, onde o fator $\mathrm{A}$ testou genótipos de eucalipto (E. globulus e $E$. saligna), o fator B comparou quatro herbicidas (isoxaflutole, oxyfluorfen, bispyribac-sodium e sethoxydim+diclosulam) e o fator $\mathrm{C}$ doses $(0,50$, 100,150 e 200\%) da dose média registrada para controle de plantas daninhas (AGROFIT, 2008). As doses dos herbicidas utilizados foram: isoxaflutole - 0; 37,5; 75; 112,5 e 150 g i.a ha-1; oxyfluorfen - $0 ; 420 ; 840 ; 1260$ e 1680 g i.a ha ${ }^{-1}$; bispyribacsodium - $0 ; 22 ; 44 ; 66$ e 88 g i.a ha-1 ${ }^{-1}$ e, sethoxydim - 0; 138; 276; 414 e 552 g i.a ha ${ }^{-1}+$ diclosulam - 0; 14,28; 28,56; 42,84 e 57,12 g i.a ha-1. Para efeito de comparação para os demais herbicidas foi utilizado o isoxaflutole como padrão.

Os tratamentos foram aplicados 10 dias após o transplante da cultura (DATC), utilizando-se pulverizador costal de precisão, pressurizado à $\mathrm{CO}_{2}$ e calibrado para aplicar volume de calda de $150 \mathrm{~L}$ $\mathrm{ha}^{-1}$, equipado com barra de quatro bicos de jato plano em leque, série 110-02, espaçados $50 \mathrm{~cm}$.

A variável fitotoxicidade às plantas de eucalipto foi quantificada por avaliação visual aos 7, 14, 21 e 28 dias após a aplicação dos tratamentos (DAT), utilizando-se escala percentual, onde zero (0) e cem (100) corresponderam à ausência de injúria e morte das plantas, respectivamente (FRANS; CROWLEY, 1986). Aos 28 DAT foram realizadas avaliações da estatura de plantas da cultura, pela utilização de régua; do diâmetro do caule da cultura a $10 \mathrm{~cm}$ do solo, com auxílio de paquímetro eletrônico digital (Starret $\left.^{\circledR} 727\right)$; e, da matéria seca da parte aérea das plantas, pela pesagem das duas plantas por vaso, e após secagem em estufa a $60^{\circ} \mathrm{C}$ por 72 horas.
Os dados obtidos foram analisados quanto a sua homocedasticidade e posteriormente submetidos à análise de variância $(\mathrm{p} \leq 0,05)$. Os efeitos de genótipos e herbicidas foram avaliados pelo teste de Tukey $(p \leq 0,05)$ e os efeitos de doses foram avaliados por modelos de regressão não linear $(\mathrm{p} \leq 0,05)$ (SigmaPlot, 1999), conforme segue:

$$
\begin{gathered}
Y=a\left(1-e^{-b x}\right) \\
Y=a e^{b x} \\
Y=y_{0}+a e^{-b x}
\end{gathered}
$$

Onde: $a=$ valor máximo e/ou mínimo estimado para a variável resposta ou parâmetro estimado pelo modelo; $b=$ inclinação da curva; $x=$ dose do herbicida ( $\mathrm{g}$ i.a ha $\left.{ }^{-1}\right) ; \mathrm{y}_{0}=$ valor mínimo estimado para a variável resposta; $\mathrm{e}=$ constante.

\section{Resultados e Discussão}

A variável fitotoxicidade à cultura, em todas as épocas de avaliação apresentou interação dos fatores genótipo, herbicida e dose (Figura 1 a 4 e Tabela 1).

O herbicida isoxaflutole, considerado como padrão, apresentou menor fitotoxicidade, para ambas as espécies estudadas (Figura 1 a 4 e Tabela 1). A máxima fitotoxicidade, estimada pelo modelo, foi observada para bispyribac-sodium independente de épocas de avaliação ou genótipo de eucalipto. Observou-se que a fitotoxicidade, estimada pelo modelo, na média dos genótipos para os herbicidas isoxaflutole, oxyfluorfen, sethoxydim+diclosulam e bispyribac-sodium, foram respectivamente: 0,8 ; 26,$7 ; 28,9$ e $52,9 \%$, aos 7 DAT; 1,$1 ; 47,7 ; 44,2$ e $75,9 \%$, aos 14 DAT; 0,$4 ; 24,1 ; 61,5$ e $78,3 \%$, aos 21 DAT e aos 28 DAT de 0,$3 ; 3,6$ e 7,4 e $77,6 \%$. 


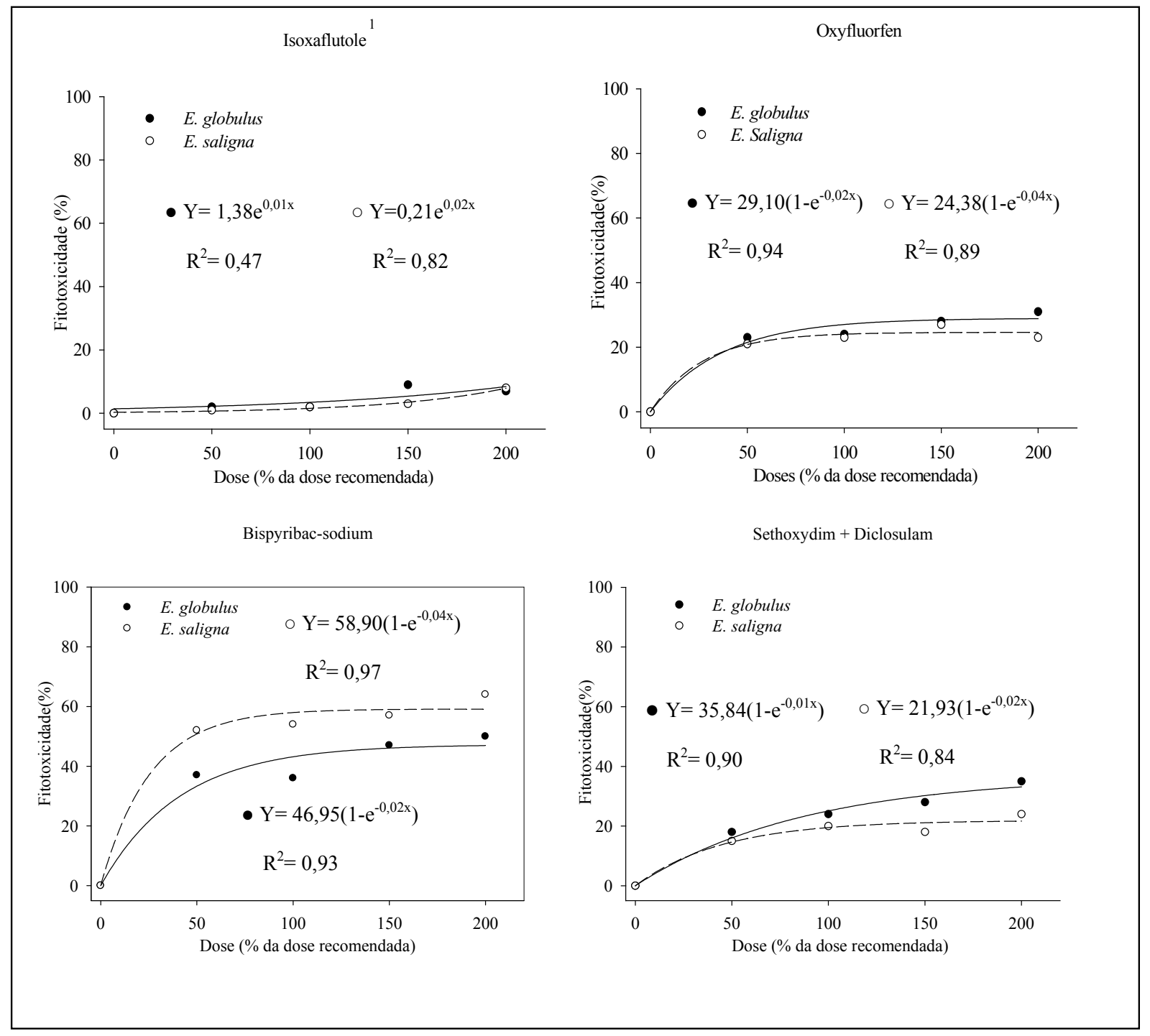

Figura 1. Fitotoxicidade de herbicidas à cultura do eucalipto, aos 7 dias após a aplicação dos tratamentos (DAT). Capão do Leão - RS, 2007. ${ }^{1}$ Isoxaflutole ( $75 \mathrm{~g}$ i.a ha $\left.{ }^{-1}\right)$, oxyfluorfen ( $840 \mathrm{~g}$ i.a ha $\left.{ }^{-1}\right)$, bispyribac-sodium (44 g i.a ha-1 $)$, sethoxydim (276 $\left.\mathrm{g}^{\text {i.a ha-1 }}{ }^{-1}\right)$ e diclosulam $\left(28,56 \mathrm{~g}^{\text {i.a }} \mathrm{ha}^{-1}\right)$. 


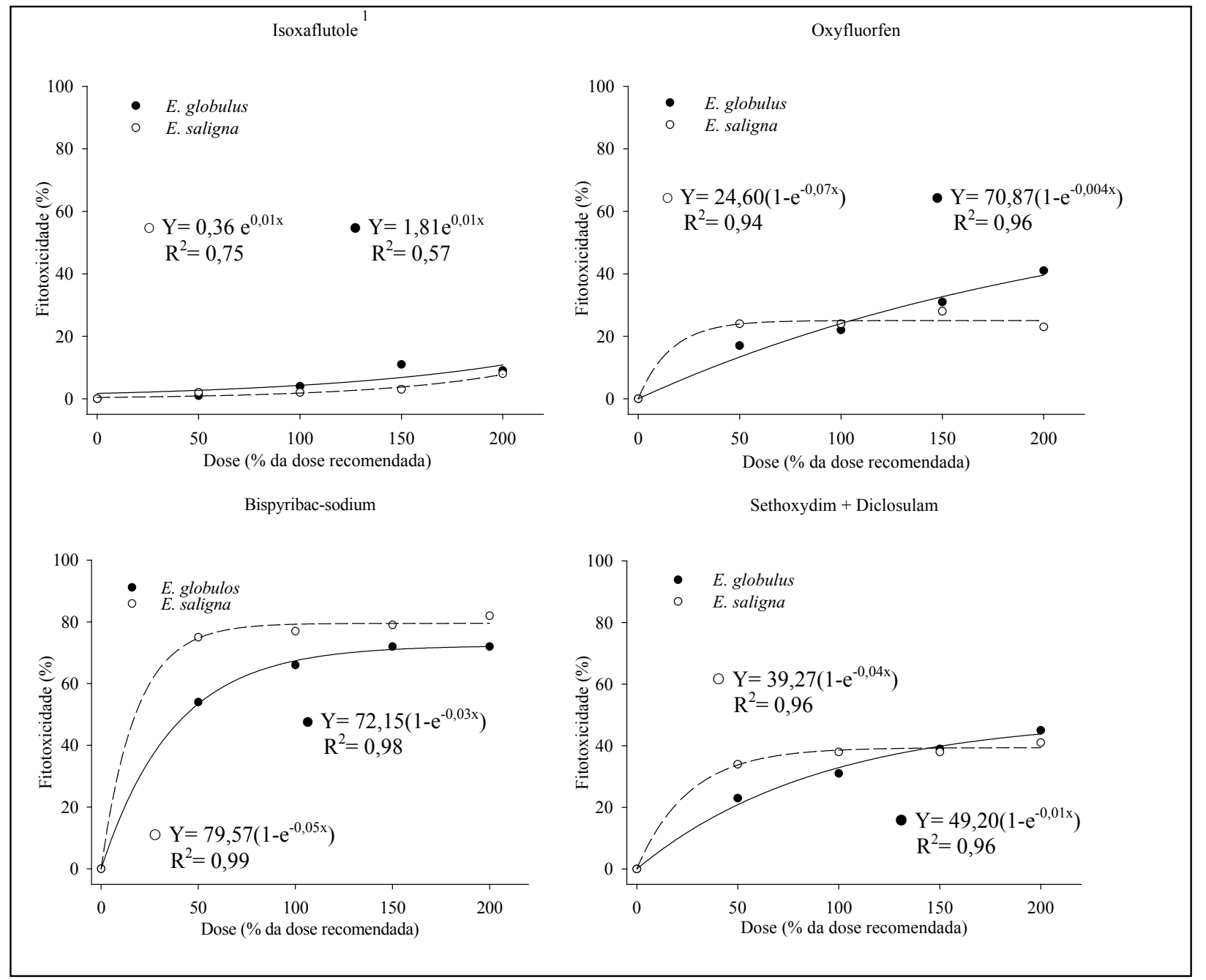

Figura 2. Fitotoxicidade de herbicidas à cultura do eucalipto, aos 14 dias após a aplicação dos tratamentos (DAT). Capão do Leão - RS, 2007. ${ }^{1}$ Isoxaflutole ( $\left.75 \mathrm{~g}^{\text {i.a }} \mathrm{ha}^{-1}\right)$, oxyfluorfen $\left(840 \mathrm{~g}\right.$ i.a ha $\left.{ }^{-1}\right)$, bispyribac-sodium (44 $\mathrm{g}$ i.a ha $\left.{ }^{-1}\right)$, sethoxydim (276 g i.a ha $\left.{ }^{-1}\right)$ e diclosulam $\left(28,56\right.$ g i.a ha $\left.{ }^{-1}\right)$. 


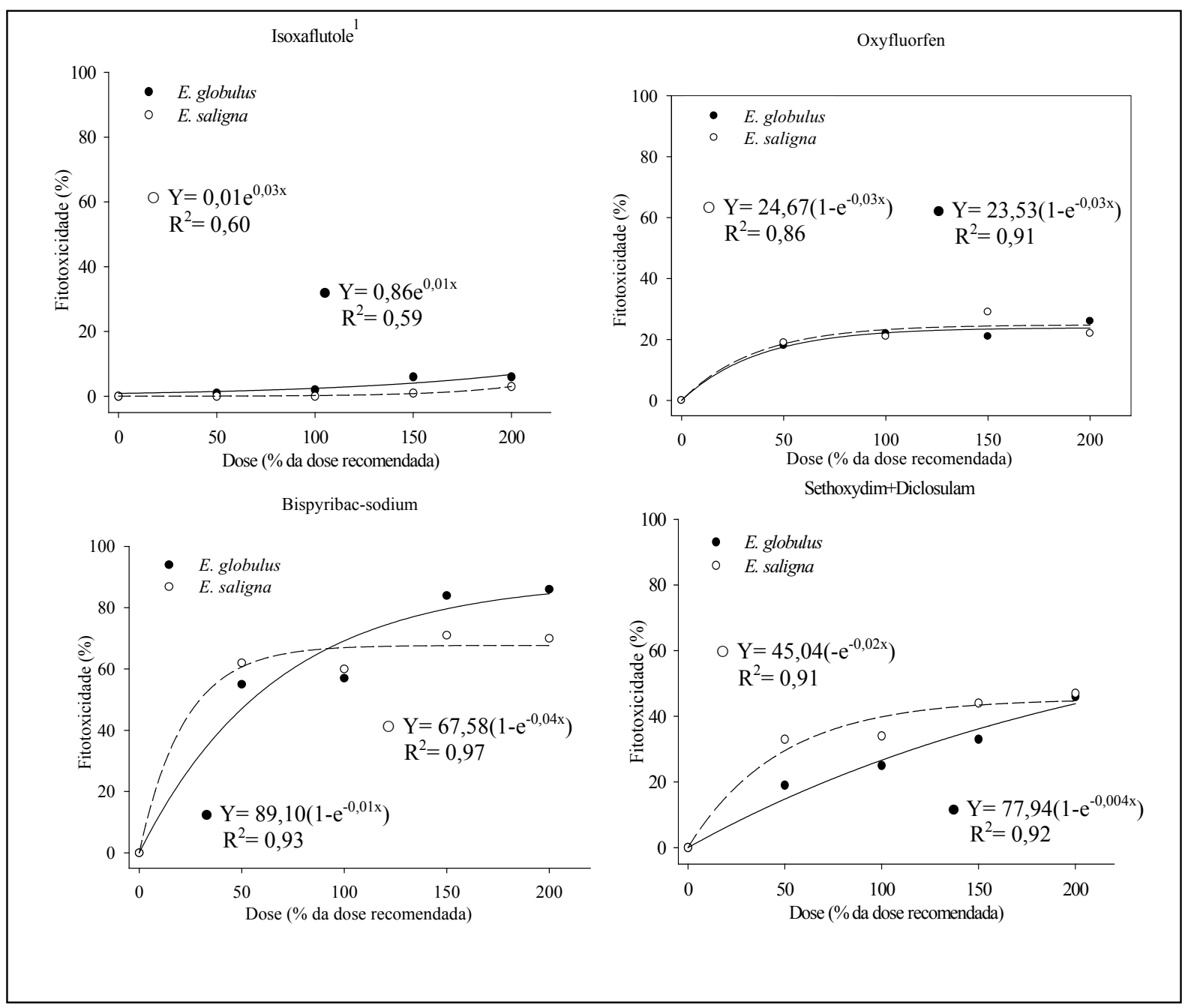

Figura 3. Fitotoxicidade de herbicidas à cultura do eucalipto, aos 21 dias após a aplicação dos tratamentos (DAT). Capão do Leão - RS, 2007. ${ }^{1}$ Isoxaflutole ( $75 \mathrm{~g}$ i.a ha $\left.{ }^{-1}\right)$, oxyfluorfen $\left(840 \mathrm{~g}\right.$ i.a ha $\left.{ }^{-1}\right)$, bispyribac-sodium (44 g i.a ha-1), sethoxydim $(276 \mathrm{~g}$ i.a ha-1 $)$ e diclosulam $\left(28,56 \mathrm{~g}\right.$ i.a ha $\left.{ }^{-1}\right)$. 


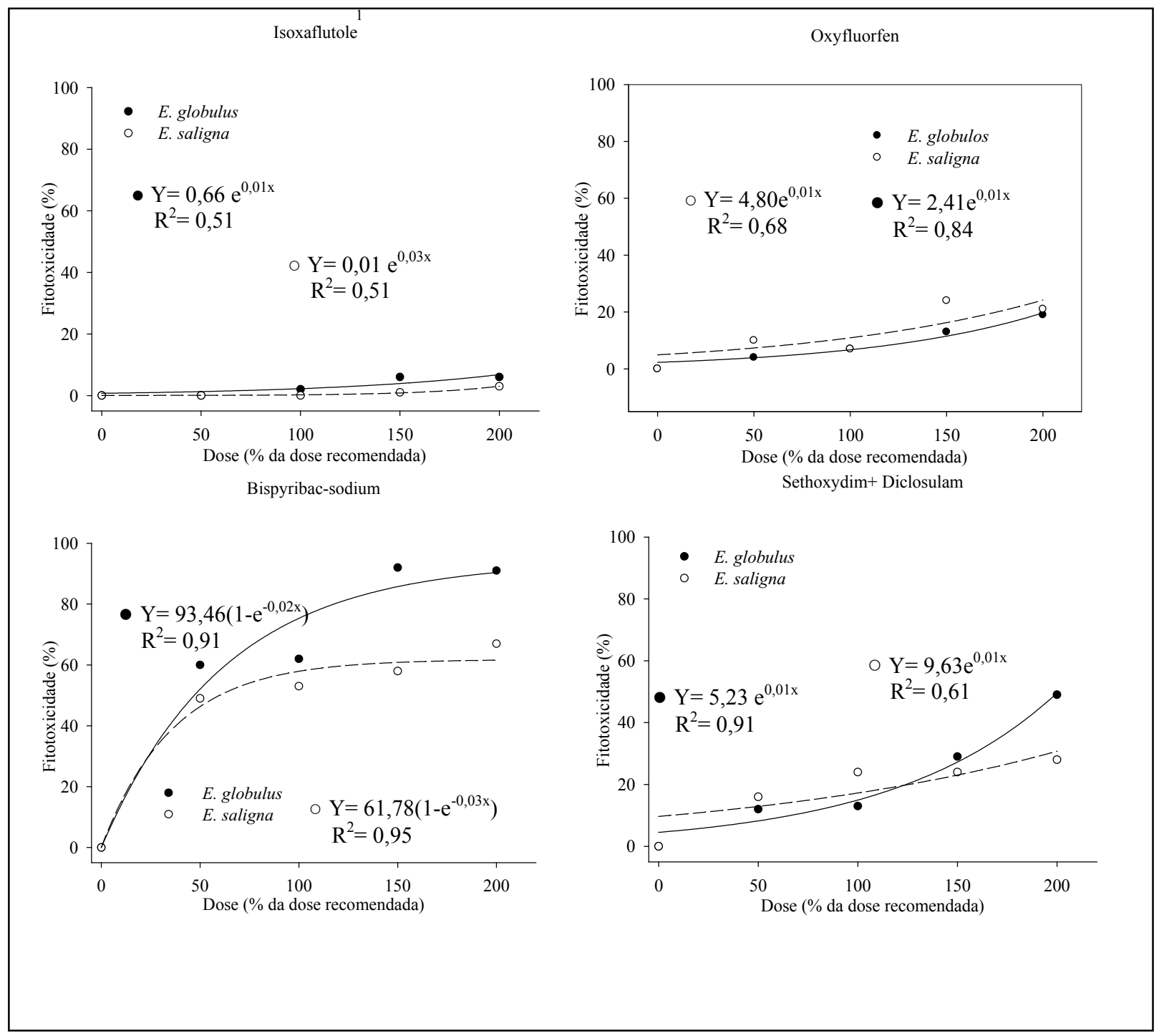

Figura 4. Fitotoxicidade de herbicidas à cultura do eucalipto, aos 28 dias após a aplicação dos tratamentos (DAT). Capão do Leão - RS, 2007. ${ }^{1}$ Isoxaflutole ( $75 \mathrm{~g}$ i.a ha $\left.{ }^{-1}\right)$, oxyfluorfen ( $840 \mathrm{~g}$ i.a ha- $\left.{ }^{-1}\right)$, bispyribac-sodium (44 g i.a ha $\left.{ }^{-1}\right)$, sethoxydim $\left(276 \mathrm{~g}\right.$ i.a ha $\left.{ }^{-1}\right)$ e diclosulam $\left(28,56 \mathrm{~g}\right.$ i.a ha $\left.{ }^{-1}\right)$. 


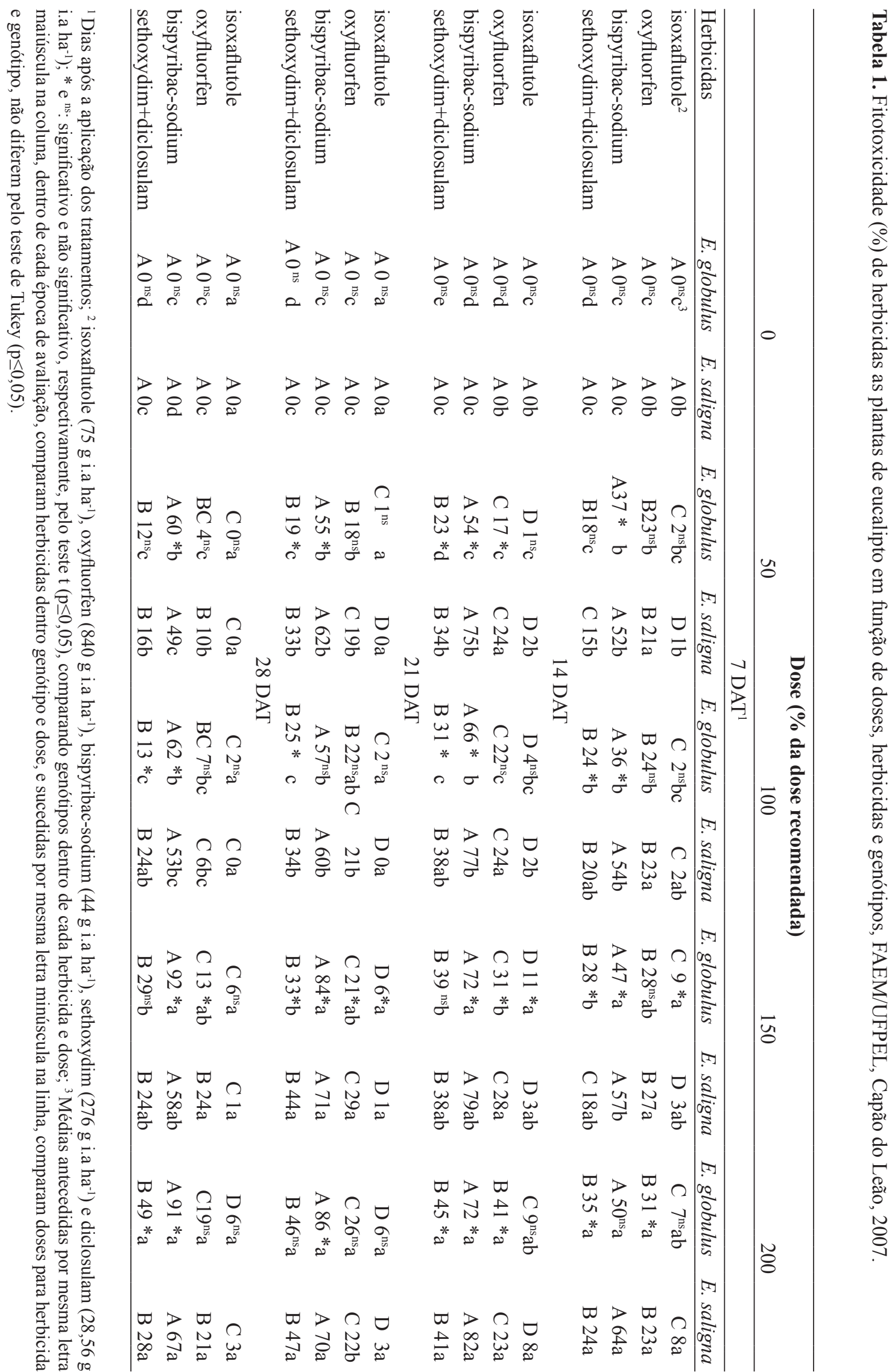


A aplicação dos herbicidas isoxaflutole, da fitotoxicidade observada para oxyfluorfen, oxyfluorfen e sulfentrazone, em E. grandis, apresentando potencial para ser utilizada na demonstrou que isoxaflutole foi seletivo para a cultura, oxyfluorfen causou sintomas leves de fitotoxicidade nas folhas, enquanto sulfentrazone, ocasionou sintomas de danos mais acentuados, comprometendo o desenvolvimento das plantas de eucalipto (ADORYAN; BENDECK; GELMINI, 2002).

Os resultados observados demonstram que os herbicidas isoxaflutole e oxyfluorfen mostraram-se seletivos à cultura. Ainda, os herbicidas possuem residual no solo, de acordo com a dosagem utilizada, permitindo controle eficiente em plantas daninhas como Brachiaria decumbens e Panicum maximum impedindonovosfluxosdestasplantas(MARCHIORI JUNIOR. et al., 2005). A utilização de oxyfluorfen na cultura do E. grandis causou clorose e necrose nas folhas das plantas, principalmente, nas mais novas existentes no momento da aplicação. Ainda assim, o oxyfluorfen pode ser recomendado para $E$. grandis em pré-emergência das plantas daninhas e após o transplante das mudas de eucalipto (SILVA et al., 1995).

O herbicida bispyribac-sodium causou a maior fitotoxicidade aos genótipos estudados (Figura 1 a 4 e Tabela 1). Embora este inibidor da enzima acetolactato sintase controle diversas espécies de plantas daninhas magnoliopsidas e liliopsidas e seja seletivo para muitas culturas, os resultados observados demonstram que esse herbicida não foi seletivo para a cultura do eucalipto.

Quanto a combinação dos herbicidas sethoxydim+diclosulam, esses causaram moderada fitotoxicidade à cultura, não diferindo cultura do eucalipto. Já, quando considerado o espectro de controle de plantas daninhas pelos herbicidas, verifica-se que o sethoxydim controla eficientemente poaceas, enquanto o diclosulam controla magnoliopsidas (AGROFIT, 2008).

$\mathrm{Na}$ média das quatro avaliações a fitotoxicidade apresentada pelos herbicidas isoxaflutole, oxyfluorfen, bispyribac-sodium e sethoxydim+diclosulam foi de 3, 17, 51 e $24 \%$, respectivamente (Tabela 1). Comparando a média das doses em todas as épocas de avaliação, observou-se que a maior dose testada ocasionou maior fitotoxicidade, na ordem de 39 e 33\%, respectivamente para os genótipos E. globulus e $E$. saligna.

A comparação entre os genótipos demonstrou que o E. globulus foi mais sensível aos herbicidas do que o E. saligna. Esta resposta pode estar relacionada a fatores genéticos que conferem maior sensibilidade ou a maior área foliar deste genótipo, permitindo maior interceptação e absorção dos herbicidas. Estas hipóteses decorrem da inexistência na literatura de trabalhos que permitam elucidar as diferenças observadas entre genótipos de eucalipto.

Para a variável matéria seca da parte aérea, houve interação dos fatores herbicida $\mathrm{x}$ dose (Figura $5 \mathrm{e}$ Tabela 2). Verificou-se ajuste dos dados ao modelo apenas para o herbicida bispyribac-sodium, sendo observado redução da variável com o incremento da dose, atingindo redução de 54\% na maior dose testada. Em trabalho utilizando oxyfluorfen com doses de 0; 360; 720; e 1080 g i.a ha ${ }^{-1}$, observou-se redução da matéria seca da parte aérea e de raízes com o incremento da dose (SILVA et al., 1994). 


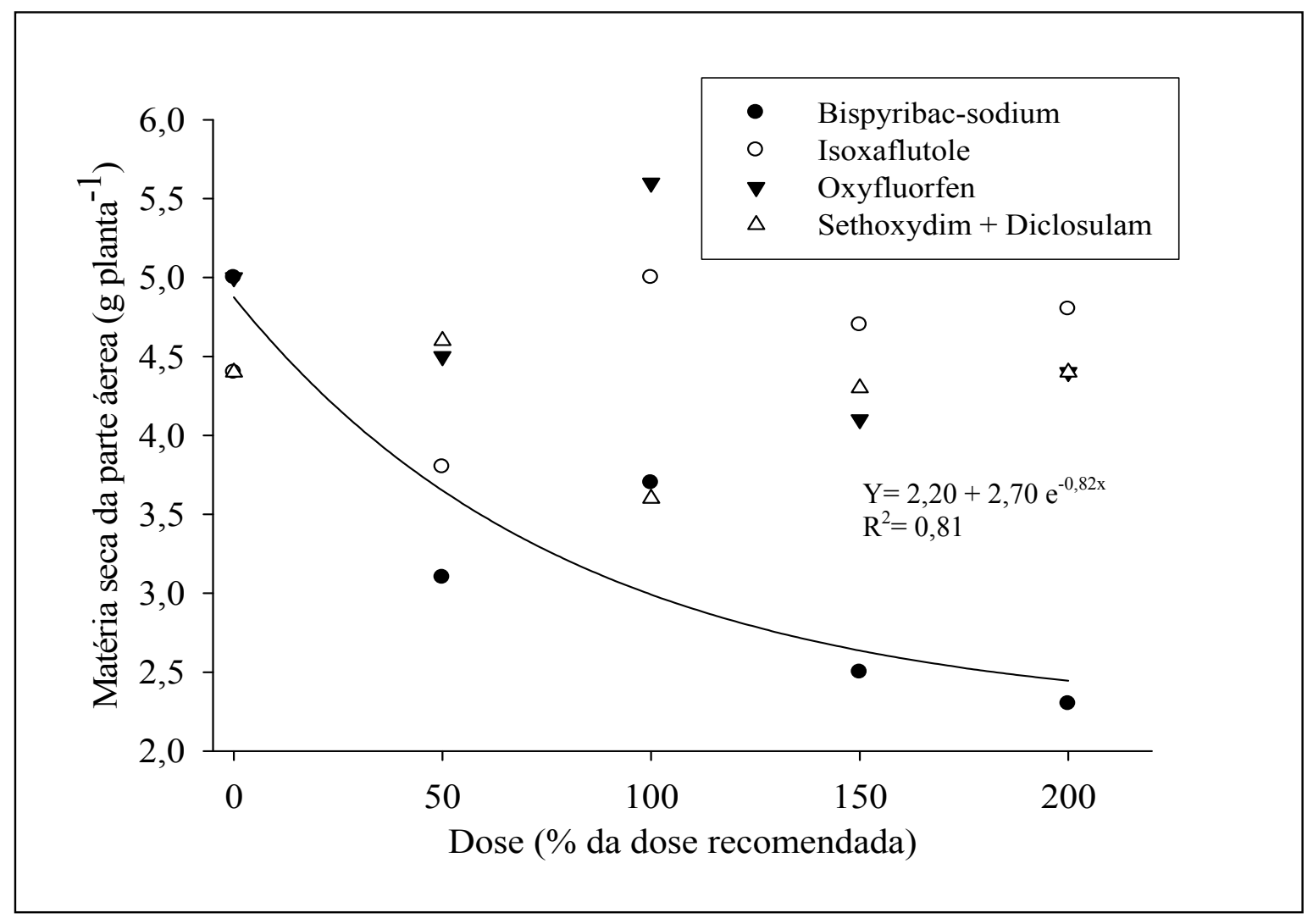

Figura 5. Matéria seca da parte aérea $\left(\mathrm{g}_{\text {planta }}{ }^{-1}\right)$ de plantas de eucalipto, em função de doses de herbicidas. Capão do Leão - RS, 2007.

Tabela 2. Matéria seca $\left(\mathrm{g}_{\text {planta }}{ }^{-1}\right)$ de plantas de eucalipto, em função de herbicidas e doses, FAEM/UFPEL, Capão do Leão/RS, 2007.

\begin{tabular}{lccccc}
\hline & \multicolumn{5}{c}{ Doses (\% da dose recomendada) } \\
\cline { 2 - 5 } Herbicidas & 0 & 50 & 100 & 150 & 200 \\
\hline isoxaflutole $^{1}$ & $4,4 \mathrm{a}^{2}$ & $4,8 \mathrm{a}$ & $5,0 \mathrm{a}$ & $4,7 \mathrm{a}$ & $4,8 \mathrm{a}$ \\
oxyfluorfen $^{2}$ & $5,0 \mathrm{a}$ & $4,5 \mathrm{a}$ & $5,6 \mathrm{ab}$ & $4,1 \mathrm{a}$ & $4,4 \mathrm{a}$ \\
bispyribac-sodium & $5,0 \mathrm{a}$ & $3,1 \mathrm{~b}$ & $3,7 \mathrm{~b}$ & $2,5 \mathrm{~b}$ & $2,3 \mathrm{~b}$ \\
sethoxydim+diclosulam & $4,4 \mathrm{a}$ & $4,6 \mathrm{a}$ & $3,6 \mathrm{~b}$ & $4,3 \mathrm{a}$ & $4,4 \mathrm{a}$ \\
\hline
\end{tabular}

${ }^{1}$ Isoxaflutole ( $75 \mathrm{~g}$ i.a ha $\left.{ }^{-1}\right)$, oxyfluorfen $\left(840 \mathrm{~g}\right.$ i.a ha $\left.{ }^{-1}\right)$, bispyribac-sodium (44 g i.a ha $\left.\mathrm{g}^{-1}\right)$, sethoxydim $\left(276 \mathrm{~g}\right.$ i.a ha $\left.{ }^{-1}\right)$ e diclosulam $\left(28,56 \mathrm{~g}_{\text {i.a ha }}{ }^{-1}\right){ }^{2}$ Médias seguidas por mesma letra minúscula na coluna, comparam herbicidas dentro de dose, não diferem pelo teste de Tukey $(\mathrm{p} \leq 0,05)$.

A variável estatura de plantas apresentou interação dos fatores herbicida $\mathrm{x}$ dose e genótipo $\mathrm{x}$ herbicida (Figura 6 e Tabela 3). Os resultados foram semelhantes aos observados para a variável matéria seca, havendo ajuste dos dados ao modelo apenas para o herbicida bispyribac-sodium e verificandose redução no crescimento à medida que a dose foi aumentada. Plantas submetidas a doses de glyphosate apresentaram menor estatura, quando submetidas às maiores dosagens (SANTOS et al., 2005). 


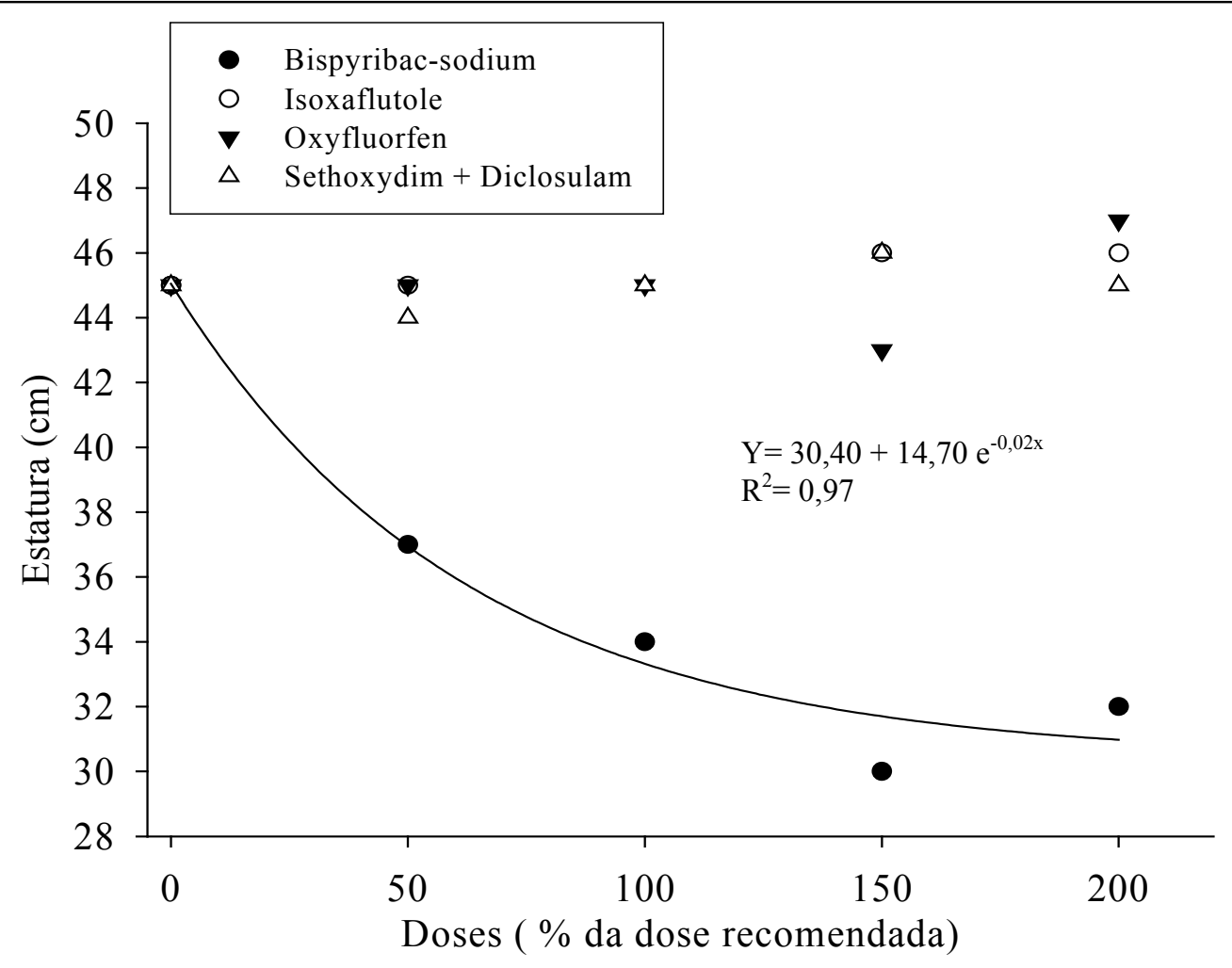

Figura 6. Estatura (cm) de plantas de eucalipto, em função doses de herbicidas. Capão do Leão - RS, 2007.

Tabela 3. Estatura (cm) de plantas de eucalipto, em função de herbicidas e doses, FAEM/UFPEL, Capão do Leão/ RS, 2007.

\begin{tabular}{lccccc}
\hline & \multicolumn{5}{c}{ Doses (\% da dose recomendada) $^{\mathbf{1}}$} \\
\cline { 2 - 5 } Herbicidas & 0 & 50 & 100 & 150 & 200 \\
\hline isoxaflutole $^{1}$ & $45 \mathrm{a}^{2}$ & $45 \mathrm{a}$ & $48 \mathrm{a}$ & $46 \mathrm{a}$ & $46 \mathrm{a}$ \\
oxyfluorfen $^{2}$ & $45 \mathrm{a}$ & $45 \mathrm{a}$ & $45 \mathrm{a}$ & $43 \mathrm{a}$ & $47 \mathrm{a}$ \\
bispyribac-sodium & $45 \mathrm{a}$ & $37 \mathrm{~b}$ & $34 \mathrm{~b}$ & $30 \mathrm{~b}$ & $32 \mathrm{~b}$ \\
sethoxydim+diclosulam $^{2}$ & $45 \mathrm{a}$ & $44 \mathrm{a}$ & $45 \mathrm{a}$ & $46 \mathrm{a}$ & $45 \mathrm{a}$ \\
\hline
\end{tabular}

${ }^{1}$ Dose de isoxaflutole (75 g i.a ha $\left.{ }^{-1}\right)$, oxyfluorfen (840 g i.a ha $\left.\mathrm{g}^{-1}\right)$, bispyribac-sodium (44 g i.a ha-1), sethoxydim (276 g i.a ha-1), diclosulam (28,56 g i.a ha-1 $) ;{ }^{2}$ Médias seguidas por mesma letra minúscula na coluna, comparam herbicidas dentro de dose, não diferem pelo teste de Tukey $(\mathrm{p} \leq 0,05)$.

$\mathrm{Na}$ comparação entre os genótipos, houve diferença para todos os herbicidas testados (Tabela 4), sendo o E. saligna, o que apresentou maior estatura. Isso pode decorrer da menor área foliar e conseqüente menor interceptação do produto ou estar relacionado a características genéticas, conforme discutido anteriormente. 
Tabela 4. Estatura $(\mathrm{cm})$ de plantas de eucalipto, em função de genótipos e herbicidas, FAEM/UFPEL, Capão do Leão/ RS, 2007.

\begin{tabular}{lcc}
\hline & \multicolumn{2}{c}{ Genótipos } \\
\cline { 2 - 3 } Herbicidas & E. globulus & E. saligna \\
\hline isoxaflutole & $* 40 \mathrm{a}^{1}$ & $52 \mathrm{a}$ \\
oxyfluorfen & $* 38 \mathrm{a}$ & $51 \mathrm{a}$ \\
bispyribac-sodium & $* 31 \mathrm{~b}$ & $40 \mathrm{~b}$ \\
sethoxydim+diclosulam & $* 39 \mathrm{a}$ & $51 \mathrm{a}$ \\
\hline
\end{tabular}

* significativo, comparam genótipos dentro de herbicida, pelo teste $\mathrm{t}(\mathrm{p} \leq 0,05) ;{ }^{1}$ Médias sucedidas por mesma letra minúscula na coluna, comparam herbicidas dentro de genótipo, não diferem pelo teste de Tukey $(\mathrm{p} \leq 0,05)$

A variável diâmetro do caule das plantas de diâmetro do caule da cultura com o incremento da eucalipto apresentou interação entre os fatores dose. Na comparação entre os genótipos ocorreu genótipo e dose (Figura 7 e Tabela 5). Houve ajuste diferença, apenas para a dose $0 \%$ e as demais não dos dados ao modelo para o fator dose apenas foram significativas (Tabela 5). para o genótipo E. globulus, ocorrendo redução do

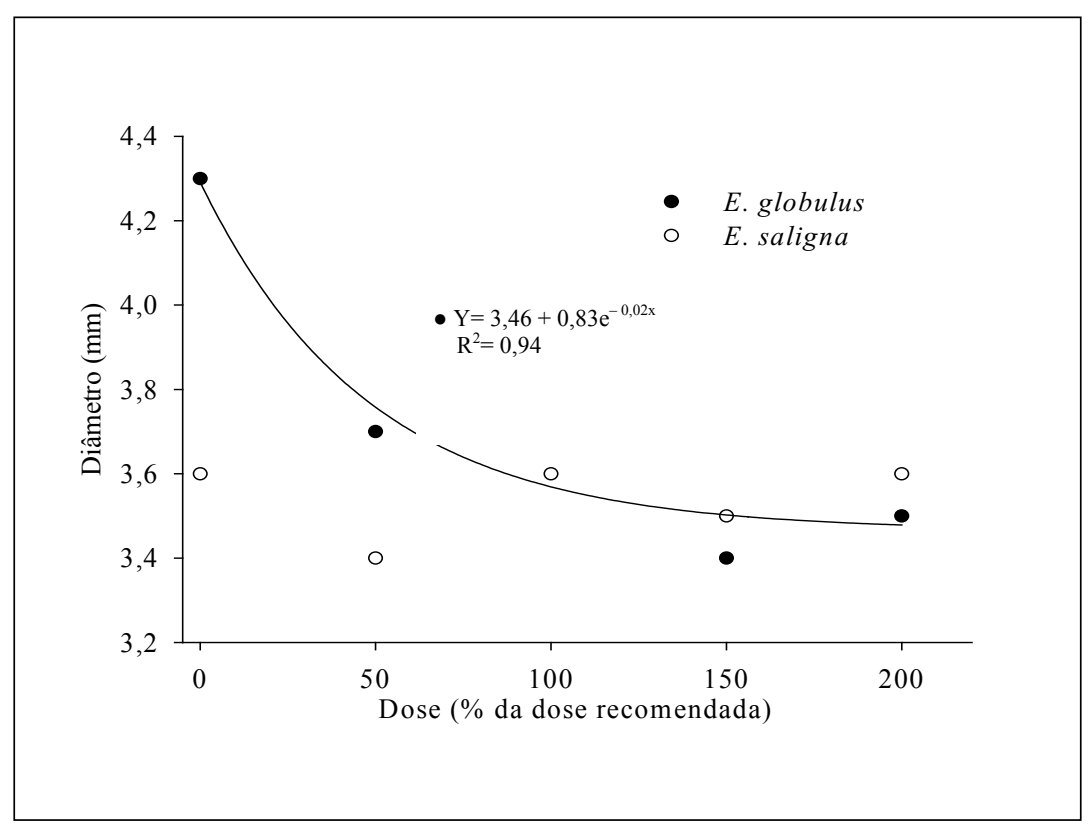

Figura 7. Diâmetro (mm) das plantas de eucalipto, em função doses de herbicidas. Capão do Leão - RS, 2007. 
Tabela 5. Diâmetro do caule $(\mathrm{mm})$ de plantas de eucalipto, em função de genótipos e doses. FAEM/UFPEL, Capão do Leão/RS, 2007.

\begin{tabular}{ccc}
\hline & \multicolumn{2}{c}{ Genótipos } \\
\cline { 2 - 3 } Doses herbicidas (\%) & E. globulus & E. saligna \\
\hline 0 & $4,3^{*}$ & 3,6 \\
50 & $3,7^{\mathrm{ns}}$ & 3,4 \\
100 & $3,7^{\mathrm{ns}}$ & 3,6 \\
150 & $3,4^{\mathrm{ns}}$ & 3,5 \\
200 & $3,5^{\mathrm{ns}}$ & 3,6 \\
\hline
\end{tabular}

* e ns: significativo e não significativo, pelo teste $\mathrm{t}(\mathrm{p} \leq 0,05)$, comparando genótipos dentro de dose.

\section{Conclusões}

O genótipo E. globulus foi mais sensível aos herbicidas testados do que o E. saligna. A mistura dos herbicidas sethoxydim+diclosulam apresentou potencial para ser utilizada na cultura do eucalipto. O herbicida bispyribac-sodium foi o mais tóxico, enquanto o isoxaflutole, considerado como padrão, foi o mais seletivo aos genótipos estudados.

\section{Referências}

ABRAF. Anuário Estatístico da Associação Brasileira de Produtores de Florestas Plantadas. Disponível em: $<$ http://www.abraflor.org.br>. Acesso em: 25 set. 2008.

ADORYAN, M. L.; BENDECK, O. B.; GELMINI, G. A. Eficácia e seletividade do herbicida isoxaflutole na cultura de Eucalyptus grandis. In: CONGRESSO BRASILEIRO DA CIÊNCIA DAS PLANTAS DANINHAS, 23., 2002, Gramado. Resumos... Gramado: Pallotti, 2002. p. 576.

AGROFIT. Sistema de Agrotóxicos Fitossanitários. Disponível em: <http://www.extranet.agricultura.gov. br>. Acesso em: 12 set. 2008.

EMPRESA BRASILEIRA DE PESQUISA AGROPECUÁRIA - EMBRAPA. Centro Nacional de Pesquisa Agropecuária de Solos (Rio de Janeiro, RJ). Sistema brasileiro de classificação de solos. Brasília: Embrapa Produção de Informação; Rio de Janeiro: Embrapa Solos, 1999. 412 p.

FRANS, R.; CROWLEY, H. Experimental design and techiques for measuring and analyzing plant responses to weed control practices. In: SOUTHERN WEED
SCIENCE SOCIETY. Research methods in weed science. 3rd ed. Champaign: Clemson, 1986. p. 29-45.

MARCHIORI JUNIOR, O.; CONSTANTIN, J.; OLIVEIRA JUNIOR, R. S.; INOUE, M. H.; PIVETTA, J. P.; CAVALIERI, S. D. Efeito residual de isoxaflutole após diferentes períodos de seca. Planta Daninha, Viçosa, v. 23, n. 3, p. 491-499, 2005.

PITELLI, R. A.; MARCHI, S. R. Interferência das plantas invasoras nas áreas de reflorestamento. In: SEMINÁRIO TÉCNICO SOBRE PLANTAS DANINHAS E O USO DE HERBICIDAS EM REFLORESTAMENTO, 3., 1991, Belo Horizonte. Anais... Belo Horizonte: SIF, 1991. p. 1-11.

PITELLI, R. A. Competição e controle das plantas daninhas em áreas agrícolas. Série Técnica IPEF, Piracicaba, v. 4, n. 12, p. 1-24, 1987.

SANTOS, L. D. T.; FERREIRA, F. A.; MEIRA, R. M. S. A.; BARROS, N. F.; FERREIRA, L. R.; MACHADO, A. F. L. Crescimento e morfoanatomia foliar de eucalipto sob efeito de deriva de glyphosate. Planta Daninha, Viçosa, v. 23, n. 1, p. 133-142, 2005.

SILVA, W.; SILVA, J. F.; CARDOSO, A. A.; BARROS, N. F. Tolerância de Eucalyptus spp. a diferentes herbicidas. Revista Árvore, Viçosa, v. 18, n. 3, p. 287-300, 1994.

SILVA, W.; SILVA, J. F.; CARDOSO, A. A.; BARROS, N. F. Utilização de trifluralin 600 e do oxyfluorfen na cultura do Eucalyptus grandis Hill e Maiden. Revista Árvore, Viçosa, v. 19, n. 1, p. 1-17, 1995.

SPADER, V.; VIDAL, R. A. Seletividade e dose de injúria econômica de nicosulfuron aplicado em diferentes estádios de desenvolvimento da cultura do milho. Ciência Rural, Santa Maria, v. 3, n. 6, p. 929-934, 2001. 
